\title{
Combined Application of Pseudomonas fluorescens and Trichoderma viride has an Improved Biocontrol Activity Against Stem Rot in Groundnut
}

\author{
K. Manjula ${ }^{1 *}$, G. Krishna Kishore ${ }^{2}$, A. G. Girish ${ }^{1}$ and S. D. Singh ${ }^{1}$ \\ 'International Crops Research Institute for the Semi-Arid Tropics (ICRISAT), Patancheru - 502 324, India \\ ${ }^{2}$ Department of Plant Sciences, University of Hyderabad, Hyderabad 500 046, India
}

(Received on November 24, 2003; Accepted on January 10, 2004)

In an attempt to develop effective biocontrol system for management of stem rot disease in groundnut, 57 bacterial isolates and 13 isolates of Trichoderma spp. were evaluated for their antagonistic activity against Sclerotium rolfsii. The antagonists were selected based on their ability to inhibit the external growth of $S$. rolfsii from infected groundnut seeds. Four isolates of Pseudomonas fluorescens, GB 4, GB 8, GB 10 and GB 27, and T. viride pq 1 were identified as potent antagonists of $S$. rolfsii. $T$. viride pq 1 produced extracellular chitinase and parasitized the mycelium of $S$. rolfsii. Under controlled environment conditions, $P$. fluorescens $\mathbf{G B}$ 10, GB 27, $T$. viride pq 1 and the systemic fungicide Thiram $^{\oplus}$ reduced the mortality of $S$. rolfsii inoculated to groundnut seedlings by $\mathbf{5 8 . 0} \%, 55.9 \%, \mathbf{7 0 . 0} \%$ and 25.9\%, respectively compared to control. In vitro growth of $P$. fluorescens GB 10 and GB 27 was compatible with T. viride pq 1 and Thiram ${ }^{\circledR}$. Integrated use of these two bacterial isolates with $T$. viride pq 1 or Thiram ${ }^{\circledR}$ improved their biocontrol efficacy. Combined application of either GB 10 or GB 27 with $T$. viride pq 1 was significantly effective than that with Thiram ${ }^{(1)}$ in protecting groundnut seedlings from stem rot infection.

Keywords : Arachis hypogaea, fungicide tolerance, peanut, sclerotia, synergism

Stem rot incited by Sclerotium rolfsii is one of the major production constraints of groundnut (Arachis hypogaea L.) in majority of the tropical and subtropical countries. Stem rot causes pod yield losses of $10-25 \%$, but under severe diseased conditions yield losses range up to $80 \%$ (Rodriguezkabana et al., 1975). Absence of potential genetic resistance in cultivated genotypes and high costs of the existing chemical control methods necessitate alternate cost-effective strategies for management of stem rot. Among the available alternate disease management options, biological control

\footnotetext{
*Corresponding author.

Present address: Centre for Cellular and Molecular Biology, Uppal Road, Hyderabad - 500 007, India

Phone: +91-040-27192505 (voice) FAX: +91-040-27160591, $+91-040-27160311 \quad$ E-mail) manjula@ccmb.res.in
}

appears promising.

Trichoderma spp. are effective in control of soil/seedborne fungal diseases in several crop plants (Kubicek et al., 2001), including groundnut (Podile and Kishore, 2002). Major mechanisms involved in the biocontrol activity of Trichoderma spp. were competition for space and nutrients, production of diffusible and/or volatile antibiotics, and hydrolytic enzymes like chitinase and $\beta$-1,3-glucanase. These hydrolytic enzymes partially degrade the pathogen cell wall and leads to its parasitization (Kubicek et al., 2001). Pseudomonas spp. are effective root colonizers and biocontrol agents, by production of antibiotics and other antifungal metabolites including antibiotics, hydrogen cyanide and siderophores (O'Sullivan and O'Gara, 1992). A positive relationship was observed between the antifungal activity of chitinolytic $P$. fluorescens isolates and their level of chitinase production (Velazhahan et al., 1999). In recent years, more emphasis is laid on the combined use of biocontrol agents with different mechanisms of disease control, for improved disease control and also to overcome the inconsistent performance of the introduced biocontrol agents.

Majority of the existing biocontrol agents for management of soil-borne diseases, were isolated from the rhizosphere. There is a possibility to explore antagonists from other habitats as potent biocontrol agents. Endophytes, which colonize and reside in the internal plant habitats were proved effective in plant growth promotion and disease control in a wide range of crops (Manjula et al., 2002). Some biocontrol agents have also been isolated from the seed surfaces (Guanlin et al., 1997).

In the present study antagonistic bacteria and Trichoderma spp. isolated from the groundnut seed were evaluated for control of $S$. rolfsii infection in groundnut under controlled environment conditions. The fungicide tolerance and in vitro compatibility of the identified biocontrol agents were determined and exploited for effective management of stem rot disease.

\section{Materials and Methods}

Fungal and bacterial isolates. Groundnut pods were collected at 
harvest from different experimental fields of the International Crops Research Institute for the Semi-Arid Tropics, Patancheru, India. The pods were sun dried and shelled under asceptic conditions. The seeds were plated on nutrient agar (NA) (Himedia, Mumbai, India) for isolation of bacteria and Trichoderma selective medium (Elad et al., 1981) for isolation of Trichoderma spp. The plates were incubated at $28^{\circ} \mathrm{C}$ for $72 \mathrm{~h}$ and observed for growth of bacteria and fungi. Single colony and single spore isolates of the observed bacteria and fungi were used in all the further experiments. $S$. rolfsii was isolated from infected groundnut seed and maintained on potato dextrose agar (PDA) (Himedia, Mumbai, India) at $4^{\circ} \mathrm{C}$.

Identification of bacterial and fungal isolates. Selected antifungal bacterial isolates were identified using NFERM bacterial diagnostic kit (LACHEMA, Czech Republic). Identification of antagonistic Trichoderma spp. was done according to the identification key proposed by Rifai (1969).

Inhibition of seed carried $S$. rolfsii. Antagonistic bacteria and Trichoderma spp. were identified by their inhibition of external growth of seed-carried $S$. rolfsii and the antifungal activity of selected isolates was reconfirmed by dual culture test. Seeds of groundnut genotype ICGS 11, infected with $S$. rolfsii were collected from a seed lot, based on the visible symptoms of infection. The seeds were surface sterilized by treatment with 100 $\mathrm{mg} / \mathrm{ml}$ chloramphenicol for $30 \mathrm{~min}$. The seeds were washed thrice with sterile distilled water and resuspended in log phase bacterial cell suspension $\left(10^{9} \mathrm{CFU} / \mathrm{ml}\right)$ in $0.5 \%$ carboxy methyl cellulose (CMC) for $5 \mathrm{~min}$. Bacterized seeds were dried under a sterile flow of air in a laminar flow. The cell number ranged from $10^{6}-10^{7}$ CFU/seed. Similarly, seeds were also suspended in a spore suspension of Trichoderma spp. $\left(10^{8}\right.$ conidia/ml $)$ in $0.5 \%$ CMC for $30 \mathrm{~min}$ and the air-dried seeds had $\sim 10^{5}$ conidia/seed. Five treated seeds were plated on water agar in $9 \mathrm{~cm}$ diameter petri plates and incubated at $28^{\circ} \mathrm{C}$. Seeds treated with $0.5 \% \mathrm{CMC}$ alone were maintained as control. Seeds were observed under a photo microscope for external growth of $S$. rolfsii, after an incubation of $72 \mathrm{~h}$. Seed germination was also recorded in each treatment. Ten seeds were maintained in each treatment and the experiment was repeated with three replications.

In dual culture test, the bacteria were streaked as a line on one edge of PDA ( $\mathrm{pH} \mathrm{6.1)} \mathrm{in} \mathrm{a} 9 \mathrm{~cm}$ diameter petri plate. After $24 \mathrm{~h}$ of incubation at $30^{\circ} \mathrm{C}$, a $7 \mathrm{~mm}$ disc of an actively growing culture of $S$. rolfsii was inoculated at the center. Plates inoculated with $S$. rolfsii alone were maintained as control. All the inoculated plates were further incubated for $72 \mathrm{~h}$ at $28^{\circ} \mathrm{C}$ and the colony diameter in each treatment was compared with that of control.

Mycelial discs of $7 \mathrm{~mm}$ diameter from actively growing cultures of $T$. viride $\mathrm{pq} 1$ and $S$. rolfsii were inoculated at either end of PDA and incubated for 7 days at $28^{\circ} \mathrm{C}$. The plates were observed at regular intervals of $24 \mathrm{~h}$ and the antifungal activity was recorded on a $1-5$ rating scale (Bell et al., 1982). PDA plates inoculated with $S$. rolfsii alone were treated as control. The above experiments were repeated with three replications.

In vitro characterization of antifungal bacteria and $T$. viride pq 1. The potent antifungal bacterial isolates were characterized for their in vitro production of hydrogen cyanide $(\mathrm{HCN})$ and chitinase. $T$. viride pq 1 was tested for production of volatile antibiotics, and hydrolytic enzymes chitinase and $\beta-1,3$-glucanase. All the experiments were repeated with three replications.

Production of HCN. For qualitative determination of the production of HCN by antagonistic bacteria, the bacteria were inoculated on NA supplemented with $4.4 \mathrm{~g} / \mathrm{l}$ glycine. Inoculated plates were inverted and a strip of sterilized filter paper saturated with $0.5 \%$ picric acid in $2 \%(\mathrm{w} / \mathrm{v})$ sodium carbonate was placed in the upper lid. The plates were then sealed with parafilm and incubated for $72 \mathrm{~h}$ at $28^{\circ} \mathrm{C}$. A change in color of the filter paper from yellow to light brown or reddish brown indicated the production of HCN (Bakker and Schippers, 1987).

Production of volatile antibiotics. The lower lids of two PDA petri plates containing PDA were inoculated separately with mycelial discs of $T$. viride pq 1 and $S$. rolfsii. The two lids were then inverted one over the other and sealed air-tight with parafilm. Plates inoculated with $S$. rolfsii and inverted over uninoculated plates were treated as control (Denis and Webster, 1971). The assembly was incubated at $28^{\circ} \mathrm{C}$ with $12 \mathrm{~h}$ photoperiod. After 96 h, colony diameter of $S$. rolfsii was measured in all the treatments. Production of chitinase. Bacteria were spotted on minimal medium with $0.1 \%(\mathrm{w} / \mathrm{v})$ colloidal chitin as a sole carbon source (Manjula, 1999). The inoculated plates were incubated for $120 \mathrm{~h}$ at $30^{\circ} \mathrm{C}$ and observed for clearing zones around the colonies.

Mycelial discs from actively growing culture of $T$. viride $\mathrm{pq} 1$ were inoculated on Richards medium (potassium nitrate - $10 \mathrm{~g}$, potassium dihydrogen orthophosphate $-5 \mathrm{~g}$, magnesium sulphate $-2.5 \mathrm{~g}$, ferric chloride $-0.02 \mathrm{~g}$ and distilled water $-1000 \mathrm{ml}$ ) with $1 \%$ colloidal chitin as sole carbon source, and incubated for $72 \mathrm{~h}$ at $28^{\circ} \mathrm{C}$ with a $12 \mathrm{~h}$ photoperiod. The plates were then observed for zone of chitin lysis around the mycelium.

Production of $\beta$-1,3-glucanase. $T$. viride $\mathrm{pq} 1$ was inoculated on RM with $1 \%(\mathrm{w} / \mathrm{v})$ lichenan and the plates were stained with $1 \%$ (w/v) congo red after an incubation for $72 \mathrm{~h}$ at $28^{\circ} \mathrm{C}$. The stained plates were observed for clear zone around the mycelial growth. Evaluation of antifungal strains for control of groundnut stem rot. Four antagonistic bacterial isolates $P$. fluorescens $\mathrm{GB} 4, \mathrm{~GB} 8$, GB 10 and GB 27, and $T$. viride pq 1 were evaluated for control of groundnut stem rot in greenhouse. Six seeds of groundnut cv. TMV 2 treated with the antagonistic bacteria and $T$. viride pq 1 were planted in $15 \mathrm{~cm}$ diameter plastic pots filled with red alfisol, farm yard manure and sand $(2: 1: 1)$. The population of the bacterial cells was $\sim 10^{7} \mathrm{CFU} / \mathrm{seed}$ and that of $T$. viride pq 1 was $\sim 10^{5}$ conidia/seed. Seeds coated with $0.5 \% \mathrm{CMC}$ were treated as control. Seed treatment with the systemic fungicide Thiram ${ }^{\circledR}$ (Sudama Chemtech P. Ltd., Gujarat, India; 75\% active ingredient), at a recommended dose of $2 \mathrm{~g} / \mathrm{kg}$ seed, was also maintained as one of the treatment to compare the disease control efficacy of biocontrol agents. At 14 days after sowing (DAS), a $1 \mathrm{~cm}$ disc of an actively growing culture of $S$. rolfsii on PDA was placed at the stem base of each plant and covered with coarse sand up to a thickness of $1.5 \mathrm{~cm}$ (Ganesan and Gnanamanickam, 1987). The sand layer was kept moist and the greenhouse temperature was maintained at $27 \pm 2^{\circ} \mathrm{C}$. Inoculated plants were observed for mortality at 15 days after inoculation (DAI). Ten plants were maintained in each treatment and the experiment was repeated 
'with three replications.

In vitro compatibility of $P$. fluorescens or $T$. viride $\mathrm{pq} 1$ and Thiram ${ }^{\circledR}$. P. fluorescens GB 10 and GB 27 effective in stem rot i:ontrol were tested for their tolerance to $T$. viride $\mathrm{pq} 1$. These three biocontrol agents were inturn tested for their tolerance to Thiram ${ }^{\circledR}$, a commonly used seed dressing fungicide. The compatibility of $P$. jluorescens isolates and $T$. viride $\mathrm{pq} 1$ was studied by co-culturing hem on PDA. The two antagonist cultures were inoculated at a distance of $2 \mathrm{~cm}$ from each other and incubated at $28^{\circ} \mathrm{C}$. Inoculated plates were observed for growth of both the cultures at egular intervals. To determine the fungicide tolerance, bacterial solates were inoculated in $50 \mathrm{ml}$ of LB broth in $250 \mathrm{ml}$ conical Tasks, added with Thiram ${ }^{8}$ at final concentrations of 5, 10, 20, 30, $50,100,250,500$ and $1000 \mu \mathrm{g} / \mathrm{ml}$. Inoculated flasks were ncubated for $48 \mathrm{~h}$ on a rotary shaker at $30^{\circ} \mathrm{C}$ and $180 \mathrm{rpm}$. The sell growth in each treatment was monitored by measuring the optical density (OD) at $420 \mathrm{~nm}$ at regular intervals of $12 \mathrm{~h}$, in somparison to control without any fungicide. Actively growing sulture of $T$. viride pq 1 was transferred to PDA added with Thiram $^{\otimes}$ at concentrations of $5-1000 \mu \mathrm{g} / \mathrm{ml}$ and incubated at $28^{\circ} \mathrm{C}$. The fungal growth was observed at $96 \mathrm{~h}$ after inoculation and sompared with control grown on PDA alone. The experiments were repeated with four replications.

Integrated use of biocontrol agents and fungicide for disease control. Groundnut seeds (cv. TMV 2) bacterized with $P$. fluorescens GB 10 and GB 27 were air-dried and coated with $T$. viride $\mathrm{pq} 1$ or Thiram ${ }^{\otimes}(2 \mathrm{~g} / \mathrm{kg}$ seed $)$ before planting. Seeds treated with either the biocontrol agents or Thiram ${ }^{\circledast}$ alone were used for zomparison and seeds treated with $0.5 \% \mathrm{CMC}$ served as control. The pathogen inoculation and disease scoring were similar to as mentioned above. Ten plants were maintained in each treatment and the experiment was repeated with three replications.

Statistical analysis. Different treatments in all the experiments were arranged in a completely randomized block design. Data from all the experiments were analyzed by analysis of variance (ANOVA) using Genstat 5 statistical package. Least significant difference (LSD) at $1 \%$ level of significance $(P=0.01)$ was used to compare the mean values of different treatments in an experiment.

\section{Results}

In vitro antifungal activity. Single colony isolates of 57 bacteria (GB 1-GB 57) and thirteen isolates of Trichoderma spp. (pq 1-pq 13) were tested for inhibition of external growth of $S$. rolfsii from groundnut seeds. In different treatments, the external growth of seed carried $S$. rolfsii was in 3.3\%-75.0\% seeds compared to $76.7 \%$ in control. Eleven isolates significantly inhibited the external growth of $S$. rolfsii and none of them inhibited the seed germination. Four bacterial isolates, $P$. fluorescens GB 4, GB 8, GB 10 and GB 27 were highly effective in inhibition of seedcarried $S$. rolfsii $\left(P_{(0.0)}=10.3\right)$. These isolates also reduced the radial growth of $S$.rolfsii in dual cultures by $>35 \%$ (Fig. $\left.1 ; P_{(0.0)}=7.6\right)$. The four bacterial isolates also increased the seed germination with $P$. fluorescens GB 27 being the most

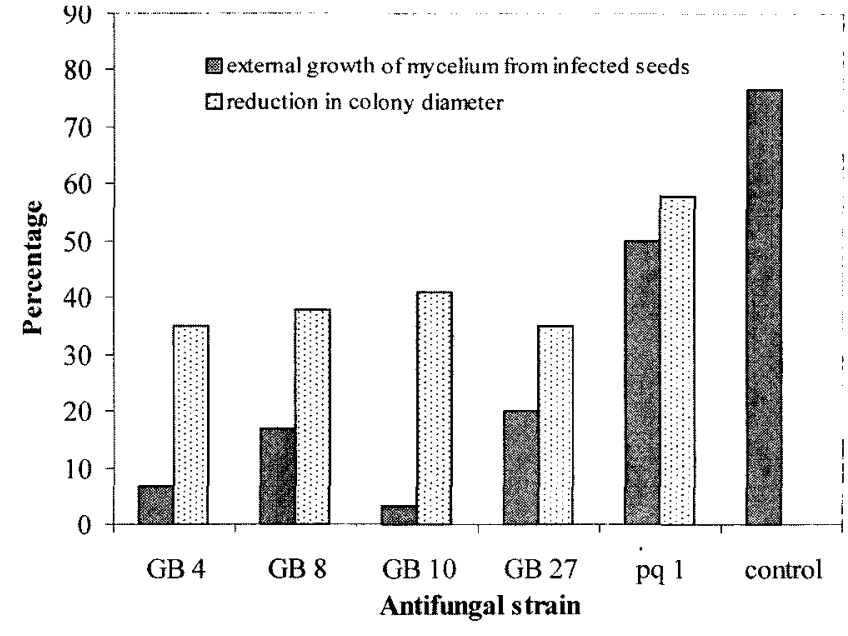

Fig. 1. Antagonistic activity of four isolates of Pseudomonas fluorescens - GB 4, GB 8, GB 10 and GB 27, and Trichoderma viride pq 1 against Sclerotium rolfsii. The antifungal activity of these isolates was determined by their inhibition of external growth of seed-carried $S$. rolfsii when applied as seed treatment and also by reduction in colony diameter in dual cultures.

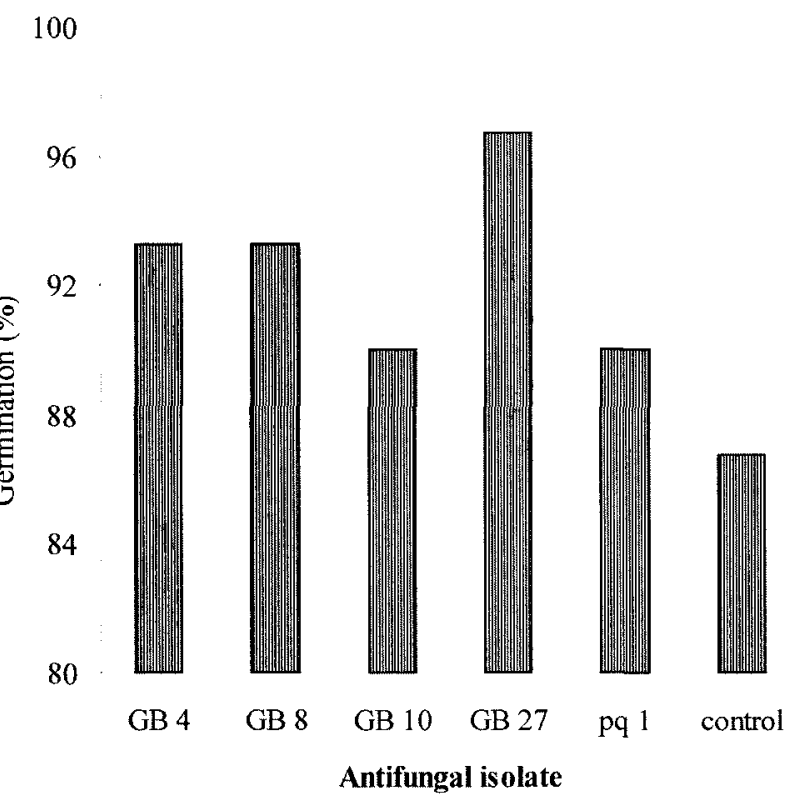

Fig. 2. Effect of the four antifungal isolates of Pseudomonas fluorescens - GB 4, GB 8, GB 10 and GB 27, and Trichoderma viride pq 1 applied as seed treatment on the in vitro germination of Sclerotium rolfsii infected groundnut seeds.

effective (Fig. 2; $P_{(0.0)}=3.1$ ).

T. viride $\mathrm{pq} 1$ inhibited the external growth of seedcarried $S$. rolfsii and its radial growth in dual cultures by $50.0 \%$ and $58.0 \%$, respectively (Fig. 1). In dual culture method T. viride pq 1 parasitized the mycelium of $S$. rolfsii and the antifungal activity was rated 4.0 on a $1-5$ rating scale. Starting from $48 \mathrm{~h}$ after inoculation, hyphae of $T$. 
Table 1. In vitro characterization of antifungal isolates of Pseudomonas fluorescens and Trichoderma viride $\mathrm{pq} 1$

\begin{tabular}{lcccc}
\hline \hline \multirow{2}{*}{ Isolate } & \multicolumn{4}{c}{ Production of } \\
\cline { 2 - 5 } & $\mathrm{HCN}^{\mathrm{a}}$ & $\begin{array}{c}\text { volatile antibi- } \\
\text { otics chitinase } \\
\text { other than }\end{array}$ & cyanide & $\begin{array}{c}\text { gluca- } \\
\text { nase }\end{array}$ \\
\hline P. fluorescens GB 4 & + & $\mathrm{ND}^{\mathrm{b}}$ & - & $\mathrm{ND}$ \\
P. fluorescens GB 8 & + & $\mathrm{ND}$ & - & $\mathrm{ND}$ \\
P. fluorescens GB 10 & + & $\mathrm{ND}$ & - & $\mathrm{ND}$ \\
P. fluorescens GB 27 & + & $\mathrm{ND}$ & - & $\mathrm{ND}$ \\
T. viride pq 1 & $\mathrm{ND}$ & + & + & - \\
\hline
\end{tabular}

${ }^{\mathrm{a}} \mathrm{HCN}=$ Hydrogen cyanide.

${ }^{\mathrm{b}} \mathrm{ND}=$ not determined.

viride pq 1 were observed to coil around $S$. rolfsii hyphae and lead to their rupture. Parasitized $S$. rolfsii failed to produce scelrotia compared to abundant sclerotial production in control.

In vitro characterization of antifungal isolates. The four antifungal bacterial isolates, $P$. fluorescens GB 4, GB 8, GB 10 and GB 27 produced $\mathrm{HCN}$ in vitro but failed to produce extracellular chitinase. In attempts to determine the production of volatile antibiotics by $T$. viride $\mathrm{pq} 1$, colony diameter of $S$. rolfsii remained the same both in presence and absence of the antagonist. Thus, production of volatile antibiotics is not involved in the antagonistic activity of $T$. viride pq 1.T. viride pq 1 produced extracellular chitinase but not $\beta$-1,3glucanase (Table 1).

Biocontrol of stem rot. In controlled environment conditions, $P$. fluorescens GB 8, GB 10 and GB 27 used as seed treatment, significantly $(P=0.01)$ reduced the mortality of groundnut seedlings by $58.0-80.0 \%$ compared to control. Among the four bacterial isolates tested, GB 10 was most effective in stem rot biocontrol, closely followed by GB 27 $\left(P_{(0.01)}=9.7\right) . T$. viride pq 1 reduced the mortality of seedlings by $>70.0 \%$ compared to control. All these biocontrol agents were significantly $(P=0.01)$ effective than Thiram ${ }^{\circledR}$, which reduced the incidence of stem rot by $25.9 \%$ (Fig. 3).

In vitro compatibility of $P$. fluorescens or $T$. viride with Thiram $^{\circledR}$. In dual cultures, P. fluorescens GB 10 and GB 27 had no effect on the growth of $T$. viride pq 1 or vice versa. The two bacterial isolates were tolerant to Thiram ${ }^{\circledR}$ at all the test concentrations, as determined by OD of the growth medium. However, Thiram ${ }^{\circledR}$ even at the lowest concentration tested $(5 \mu \mathrm{g} / \mathrm{ml})$, completely inhibited the growth of $T$. viride pq 1.

Combined application of $P$. fluorescens and $T$. viride pq 1 or Thiram $^{\circledR}$ for management of stem rot. Isolates of $P$. fluorescens GB 10 or GB 27 applied in combination with $T$. viride $\mathrm{pq} 1$ were significantly effective $(P=0.05$ and 0.01 for GB 10 and GB 27, respectively, and based on the mortality value) than each bacterial isolate, $T$. viride pq 1 or Thiram ${ }^{\circledR}$

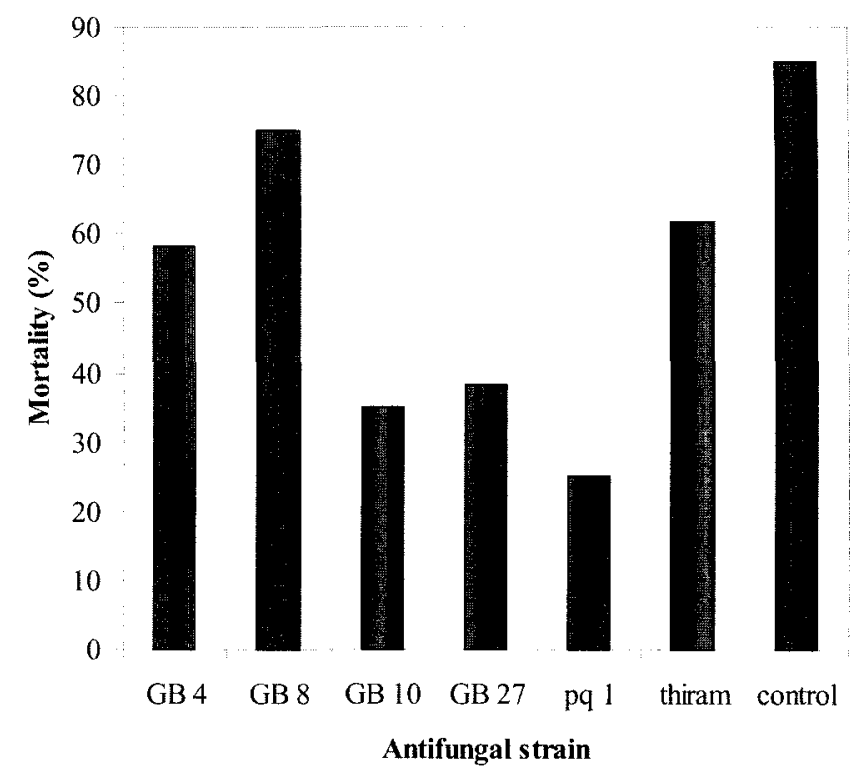

Fig. 3. Biocontrol potential of four antifungal isolates of Pseudomonas fluorescens - GB 4, GB 8, GB 10 and GB 27, and Trichoderma viride pq 1, applied as seed treatment, against stem rot infection in groundnut under controlled environment conditions. The antagonists were applied as seed treatment and at 14 days after sowing the seedlings were inoculated with Sclerotium rolfsii. Mortality of the inoculated plants was recorded at 15 days after inoculation.

in protecting the groundnut seedlings from stem rot infection. Furthermore, combined application of either of the bacterial isolate with $T$. viride $\mathrm{pq} 1$ was effective than their combined application with Thiram ${ }^{\circledR}$. Of all the

Table 2. Biological control of groundnut stem rot by the combined application of Pseudomonas fluorescens GB 10 or GB 27 and Trichoderma viride pq 1 or Thiram ${ }^{\circledR}$

\begin{tabular}{|c|c|}
\hline Treatment & $\begin{array}{c}\text { Mortality } \\
\left.\text { (percentage control }^{2}\right)(\%)\end{array}$ \\
\hline P. fluorescens GB 10 & $35.0(58.0)$ \\
\hline P. fluorescens $\mathrm{GB} 10+T$. viride $\mathrm{pq} 1$ & $18.3(78.0)$ \\
\hline P. fluorescens GB $10+$ Thiram $^{\circledR}$ & $28.3(66.0)$ \\
\hline P. fluorescens GB 27 & $36.7(55.9)$ \\
\hline P. fluorescens $\mathrm{GB} 27+T$. viride $\mathrm{pq} 1$ & $16.7(80.4)$ \\
\hline P. fluorescens GB $27+$ Thiram $^{\circledR}$ & $23.3(72.0)$ \\
\hline T. viride $\mathrm{pq} 1$ & $25.0(70.0)$ \\
\hline Thiram $^{\circledR}$ & $61.7(25.9)$ \\
\hline Control & $83.3(0.0)$ \\
\hline $\operatorname{LSD}(P=0.01)$ & 7.63 \\
\hline
\end{tabular}

${ }^{a}$ Values in the parenthesis are the percentage disease control in each treatment over control. All the values are the mean of six replicates in two separate sets of experiments.

The two bacterial isolates had an in vitro compatibility with $T$. viride and Thiram ${ }^{\circledast}$. All the treatments were applied as seed treatment and Sclerotium rolfsii was inoculated at 14 days after sowing. Mortality of the inoculated plants was observed at 15 days after inoculation. 
different treatments, a combination of $P$. fluorescens GB 27 and $T$. viride $\mathrm{pq} 1$ had the highest disease control ability (Table 2).

\section{Discussion}

An important finding of the present study is the identification of seed-associated microorganisms as biocontrol agents, which has not received much attention in the past. Though, we have not compared the efficacy of these microorganisms with those from other habitats, the results obtained indicate that seed-associated microorganisms can be a potential source of biocontrol agents. Microbial strains adapted to colonize the seed surface may also have an additional advantage in colonizing the plant root system by using the limited available nutrients and root exudates.

Inhibition of seed-carried $S$. rolfsii was used as a selection method to identify potent antifungal strains, as this system to some extent mimics the natural antagonism, though in majority of the instances stem rot infection in groundnut is due to soil-borne inoculum. The antifungal strains identified by this selection method also significantly inhibited $S$. rolfsii in the dual culture method. In dual culture assay, $T$. viride $\mathrm{pq} 1$ inhibited the growth of $S$. rolfsii, parasitized and lysed the mycelium of $S$. rolfsii. Trichoderma spp. were known to penetrate and colonize both the sclerotia and mycelium of $S$. rolfsii (Henis et al., 1983). Degradation of chitin in the cell walls of $S$. rolfsii by chitinases of Trichoderma spp., facilitates their penetration of S. rolfsii mycelium (Haran et al., 1996). Since, sclerotia are the perennating bodies, which carry $S$. rolfsii from one season to the other, inhibition of sclerotial production can reduce the over all available inoculum of $S$. rolfsii in field.

Pseudomonas spp. are well known for production of broad spectrum antibiotics such as 2,4-diacetyl phloroglucinol and antibiosis was proved to be a major mechanism involved in their biocontrol activity (O'Sullivan and O'Gara, 1992). HCN and siderophores produced by Pseudomonas spp. were also involved in their antifungal activity. Voisard et al. (1989) observed that the suppression of black rot of tobacco was due to the production of $\mathrm{HCN}$ by $P$. fluorescens, and also HCN induced resistance in the host plant. A leaf colonizing Pseudomonas sp. constructed to overproduce $\mathrm{HCN}$ protected wheat from a leaf pathogen, Septocia tritici more effectively than the parent strain (Flaishman et al., 1996). In the present study, the four selected antifungal $P$. fluorescens isolates were observed to produce $\mathrm{HCN}$ in vitro, which might have contributed for their biocontrol ability in addition to antibiotics.

P. fluorescens GB 10, GB 27 and T. viride pq 1 were significantly effective than Thiram ${ }^{\oplus}$ in control of stem rot. Different isolates of $P$. fluorescens and Trichoderma spp. were identified as biocontrol agents of groundnut stem rot and other soil-borne diseases (Podile and Kishore, 2002; Ganesan and Gnanamanickam, 1987). In contrast to the mycelial inhibition in dual cultures, the four $P$. fluorescens isolates differed in their biocontrol ability possibly due to the differences in root colonization and production of antifungal metabolites in natural environments.

Synergism between different biocontrol agents and their compatibility with fungicides was often observed as an effective means for their integration with the existing disease management practices. Combined application of $P$. fluorescens $\mathrm{GB} 10$ or GB 27 and T. viride pq 1 resulted in improved biocontrol than the combined application of GB 10 or GB 27 and Thiram ${ }^{\circledR}$. Jetiyanon and Kloepper (2002) proposed a combinational use of different biocontrol agents for improved and stable biocontrol agents against a complex of diseases. Our results support the earlier observations that a combination of biocontrol agents with different mechanisms of disease control will have an additive effect and results in enhanced disease control compared to their individual application (Guetsky et al., 2002). The present study identified additional biocontrol agents for control of groundnut stem rot, which can be easily and stably integrated into the existing production practices.

\section{References}

Bakker, A. W. and Schippers, B. 1987. Microbial cyanide production in the rhizosphere in relation to potato yield reduction and Pseudomonas spp-mediated plant growth-stimulation. Soil Biol. Biochem. 19:451-457.

Bell, D. K., Wells, H. D. and Markham, C. R. 1982. In vitro antagonism of Trichoderma spp. against six fungal pathogens. Phytopathology 72:379-382.

Denis, C. and Webster, J. 1971. Antagonistic properties of some groups of Trichoderma I-II. Trans. Br. Mycol. Soc. 57:41-48.

Elad, Y., Chet, I. and Henis, Y. 1981. A selective medium for improving quantitative isolation of Trichoderma spp. from soil. Phytoparasitica 9:59-67.

Flaishman, M. A., Eyal, Z., Zilberstein, A., Voisard, C. and Haas, D. 1996. Suppression of Septoria tritici blotch and leaf rust of wheat by recombinant cyanide producing strains of Pseudomonas putida. Mol. Plant-Microbe Interact. 9:642-645.

Ganesan, P. and Gnanamanickam, S.S. 1987. Biological control of Sclerotium rolfsii in peanut by inoculation with Pseudomonas fluorescens. Soil Biol. Biochem. 19:35-38.

Guanlin, X., Pamplona, R., Cottyn, B. and Mew, T. W. 1997. Rice seed- Source of naturally occurring biological control agents. In: Plant Growth Promoting Rhizobacteria: Present Status and Future Prospects, ed. by A. Ogoshi, K. Kobayashi, Y. Homma, F. Kodama, N. Kondo, and S. Akino. Proceedings of the Fourth International Workshop on Plant Growth Promoting Rhizobacteria, Sapporo, Japan. pp. 445.

Guetsky, R., Stienberg, D., Elad, Y., Fischer, E. and Dinoor, A. 
2002. Improving biological control by combining biocontrol agents each with several mechanisms of disease suppression. Phytopathology 92:976-985.

Haran, S., Schickler, H., Oppenheim, A. and Chet, I. 1996. Differential expression of Trichoderma harzianum chitinases during mycoparasitism. Phytopathology 86:980-985.

Henis, Y., Adams, P. B., Lewis, J. A. and Papavizas, G. C. 1983. Penetration of sclerotia of Sclerotium rolfsii by Trichoderma spp. Phytopathology 73:1043-1046.

Jetiyanon, K. and Kloepper, J. W. 2002. Mixtures of plant growthpromoting rhizobacteria for induction of systemic resistance against multiple plant diseases. Biol. Cont. 24:285-291.

Kubicek, C. P., Mach, R. L., Peterbauer, C. K. and Lorito, M. 2001. Trichoderma: From genes to biocontrol. J. Plant Pathol. 83:11-23.

Manjula, K., Singh, S. D. and Kishore, G. K. 2002. Role of endophytic bacteria in biological control of plant diseases. Annu. Rev. Plant Pathol. 1:231-252.

Manjula, K. 1999. Characterization of chitinolytic ability of Bacillus subtilis AF 1 and its use in development of improved formulation for plant growth promotion and disease control. Ph.D. thesis, University of Hyderabad, Hyderabad 500 046, India.
O'Sullivan, D. J. and O'Gara, F. 1992. Traits of fluorescent Pseudomonas spp. involved in suppression of plant root pathogens. Microbiol. Rev. 56:662-676.

Podile, A. R. and Kishore, G. K. 2002. Biological control of peanut diseases. In: Biological control of crop diseases, ed. by S.S. Gnanamanickam. Marcel Dekker, Inc., New York, pp. 131-160.

Rifai, M. A. 1969. A revision of the genus Trichoderma. Mycological papers, No. 116. Commonwealth Mycological Institute, Association of Applied Biologists, Kew, Surrey, England.

Rodriguez-kabana, R., Backman, P. A. and Williams, J. C. 1975. Determination of yield losses due to Sclerotium rolfsii in peanut fields. Plant Dis. Rept. 59:855-858.

Velazhahan, R., Samiyappan, R. and Vidhyasekaran, P. 1999. Relationship between antagonistic activities of Pseudomonas fluorescens isolates against Rhizoctonia solani and their production of lytic enzymes. Zeitscrift fur Pflanzenkrankheiten und Pflanzenschutz. 106:244-250.

Voisard, C., Keel, C., Haas, D. and Defago, G. 1989. Cyanide production by Pseudomonas fluorescens helps suppress black root rot of tobacco under gnotobiotic conditions. EMBO J. 8:351-358. 